\title{
Male mice with deleted Wolframin (Wfsl) gene have reduced
} fertility

\author{
Klari Noormets*1, Sulev Kõks 2,3, Ants Kavak³, Andres Arend ${ }^{4}$, \\ Marina Aunapuu ${ }^{4}$, Aivi Keldrimaa ${ }^{1}$, Eero Vasar ${ }^{2}$ and Vallo Tillmann ${ }^{1}$
}

Address: ${ }^{1}$ Department of Paediatrics, University of Tartu, 6 Lunini Street, 51014 Tartu, Estonia, ${ }^{2}$ Department of Physiology, University of Tartu, 19 Ravila Street, 50411 Tartu, Estonia, ${ }^{3}$ Institute of Veterinary Medicine and Animal Sciences, Estonian University of Life Sciences, 62 Kreutzwaldi Street, 51014 Tartu, Estonia and ${ }^{4}$ Department of Anatomy, Chair of Histology and Embryology, University of Tartu, 19 Ravila Street, 50411 Tartu, Estonia

Email: Klari Noormets* - klari.noormets@ut.ee; Sulev Kõks - sulev.koks@ut.ee; Ants Kavak - ants.kavak@emu.ee; Andres Arend - andres.arend@ut.ee; Marina Aunapuu - marina.aunapuu@ut.ee; Aivi Keldrimaa - aivi.keldrimaa@mail.ee; Eero Vasar - eero.vasar@ut.ee; Vallo Tillmann - vallo.tillmann@kliinikum.ee

* Corresponding author

Published: 10 August 2009

Reproductive Biology and Endocrinology 2009, 7:82 doi:10.1/86/1477-7827-7-82

This article is available from: http://www.rbej.com/content/7/I/82

(c) 2009 Noormets et al; licensee BioMed Central Ltd.

This is an Open Access article distributed under the terms of the Creative Commons Attribution License (http://creativecommons.org/licenses/by/2.0), which permits unrestricted use, distribution, and reproduction in any medium, provided the original work is properly cited.
Received: 19 March 2009

Accepted: 10 August 2009

\begin{abstract}
Background: Wolfram Syndrome (WS) is an autosomal recessive disorder characterised by nonautoimmune diabetes mellitus, optic atrophy, cranial diabetes insipidus and sensorineural deafness. Some reports have described hypogonadism in male WS patients. The aim of our study was to find out whether WfsI deficient (WfsIKO) male mice have reduced fertility and, if so, to examine possible causes.
\end{abstract}

Methods: Wfs IKO mice were generated by homologous recombination. Both Wfs IKO and wild type $(w t)$ male mice were mated with wt female mice. The number of litters and the number of pups were counted and pregnancy rates calculated. The motility and morphology of the sperm and the histology of testes were analysed. Serum testosterone and FSH concentrations were also measured.

Results: The pregnancy rate in wt females mated with Wfs IKO males was significantly lower than in the control group ( $15 \%$ vs. $32 \%$; $p<0.05)$, but there was no significant difference in litter size. Analysis of male fertility showed that, in the WfsIKO group, eight males out of 13 had pups whereas in the control group all 13 males had at least one litter. Sperm motility was not affected in Wfs IKO mice, but Wfs IKO males had less proximal bent tails $(14.4+/-1.2 \%$ vs. $21.5+/-1.3 \mathrm{P}$ $<0.05)$ and less abnormal sperm heads $(22.8+/-1.8 \mathrm{vs.} 31.5+/-3.5, p<0.05)$ than wt males. Testes histology revealed significantly reduced number of spermatogonia $(23.9+/-4.9$ vs. $38.1+/-2.8 ; p<$ $0.05)$ and Sertoli cells $(6.4+/-0.5$ vs. $9.2+/-1.0 ; p<0.05)$ in Wfs IKO mice. Serum testosterone and FSH concentrations did not differ between the two groups.

Conclusion: The impaired fertility of Wfs IKO male mice is most likely due to changes in sperm morphology and reduced number of spermatogenic cells. The exact mechanism through which the Wfs I gene influences sperm morphology needs to be clarified in further studies. 


\section{Background}

Wolfram syndrome (WS), also known as DIDMOAD syndrome, was first described by Wolfram and Wagener in 1938. It is an autosomal recessive disorder usually diagnosed in childhood when non-autoimmune type I diabetes occurs with optic atrophy, cranial diabetes insipidus and sensorineural deafness [1,2]. Other abnormalities related to this syndrome are dilated renal outflow tracts, multiple neurological abnormalities and various neurological and psychiatric disorders [2-5]. Involvement of the hypothalamus, brain stem (central sleep apnoea), and cerebellum (ataxia) may develop in the third decade or later [1].

Wolfram syndrome is caused by mutation in the Wfs 1 gene on chromosome 4p16 [6]. This gene is responsible for encoding wolframin, a glycoprotein of the endoplasmic reticulum, although the function of the wolframin protein is not fully understood [7-9]. There is growing evidence that $W f_{s} 1$ plays an important role in the pathogenesis of endoplasmic reticulum (ER) stress and apoptosis [8-10]. Genetic association studies have also indicated the role of $W f s 1$ in the development of type 2 diabetes [11].

As yet there has been no data regarding the fertility of patients with WS. Previous studies have described anterior pituitary dysfunction [5] and, in male patients, the presence of primary gonadal atrophy and hypergonadotropic hypogonadism [2-5]. As far as we know, the role of the $W f_{s} 1$ gene in fertility has not been studied.

Mice lacking the $W f s 1$ gene (Wfs $1 \mathrm{KO}$ ) were created at the Laboratory of Physiology, University of Tartu [12]. This animal model of WS is useful to study the various organsystems of WS, including fertility.

The aim of our study was to determine whether the fertility of Wfs $1 \mathrm{KO}$ male mice is reduced and if so, to explore possible reasons. Regarding the possible causes of impaired fertility, we have focused on sperm morphology.

\section{Methods \\ Animals}

In accordance with the European Communities Directive (86/609/EEC), the Estonian National Board of Animal Experiments granted permission (No. 86, 28.08. 2007) for the animal experiments described in this study. Mice were housed under standard laboratory conditions on a 12-hour light/dark cycle (lights on at 07:00 hours) with free access to food and water.

$W f s 1$ deficient (Wfs1KO) mice were generated by targeting construct to replace most of the coding region of the $w f s 1$ gene (Figure 1). Briefly, the $8.8 \mathrm{~kb} \mathrm{BamHI}$ restriction fragment from the PAC clone 391-J24 (RPCI21 library, MRC UK HGMP Resource Centre, UK) was subcloned into a pGem 11 cloning plasmid (Promega, Madison, WI). We replaced the 3.7-kb NcoI fragment with an in-frame NLSLacZNeo cassette. This resulted in the deletion of amino acids 360-890 in the Wfs1 protein and a fusion between the Wfs1 1-360 fragment and LacZ. This construct was inserted into W4/129S6 embryonic stem (ES) cells (Taconic, Hudson, NY) at the Biocenter of the University of Oulu http://www.biocenter.oulu.fi. Colonies resistant to G418 and gancyclovir were screened for homologous recombination by polymerase chain reaction (PCR) by using the recombination-specific primers NeoR1 5'GACCGCTATCAGGACA TAGCG3' and Wfs1_WTR1 5'AGGACTCAGGTTCTGCCTCA3' (Figure 2 ). We sequenced the PCR product to verify that homologous recombination took place, and injected ES clone 8A2 into $\mathrm{C} 57 \mathrm{BL} / 6$ blastocysts. The invalidation of $\mathrm{Wfs} 1$ gene was verified by mRNA expression analysis and we confirmed the lack of Wfs 1 transcript in homozygous Wfs 1 mutant mice [13] (Figure 3).

According to the Mouse Genome Database http:// www.informatics.jax.org/, the official designation of this strain is Wfs $1 \mathrm{tm} 1$ Koks. In order to avoid the "congenic footprint" effect [14] we bred animals into two different backgrounds and only used mice with the isogenic 129 S6 background.

\section{Fertility study}

We used $13 \mathrm{Wfs} 1 \mathrm{KO}, 13$ wild type (wt) male mice and 156 wt female mice. All mice were 8-12 weeks old. All male mice, both wt and Wfs $1 \mathrm{KO}$, were housed in one cage with two wt female mice each. Every morning the females were checked for the presence of vaginal plugs, an indication that sexual activity had taken place. If a vaginal plug was present, the female was taken away from the cage and placed in another one. If there was no vaginal plug after three days, the mice were separated and two other females were introduced to the males. This was done three times. Thus, at the end of the period, six females had been introduced to each male mouse $(6 \times 13 \times 2)$. Each week, every female was weighed and if they had gained weight they were transferred to a single cage, where they delivered their pups. The fertility rate and the size of the litter were counted for each male.

\section{Sperm morphology and motility study}

Sperm were obtained from the cauda epididymides of mature male mice ( $11 \mathrm{Wfs} 1 \mathrm{KO}$ and $12 \mathrm{wt}$ ) previously killed by cervical dislocation. Two hundred spermatozoa per male were analysed, totalling 2200 spermatozoa in the Wfs $1 \mathrm{KO}$ group and 2400 in the control group. Sperm motility was observed and recorded by CASA (Sperm Vision $^{\mathrm{Tm}}$, Minitübe, Germany). The percentage of motile spermatozoa and straight line motile spermatozoa was calculated. Sperm morphology was studied on wet preparations made from formol-saline fixed samples, under 


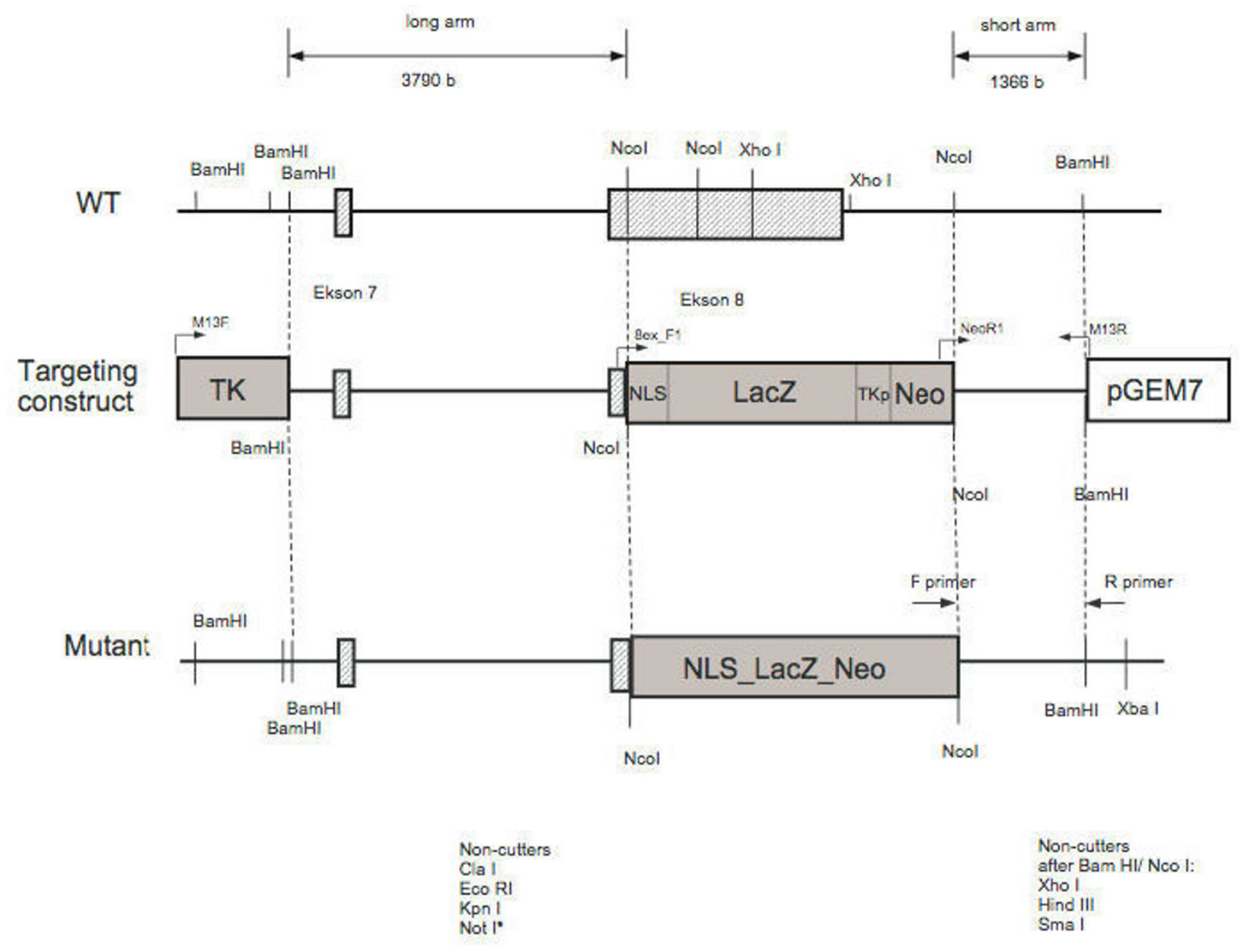

Figure I

The Wfs I targeting vector was designed to replace exon 8 in the wfs I gene with the NLS-LacZ-Neo expression cassette.

phase-contrast microscope at $1000 \times$ magnification. The sperm head morphology, sperm tail morphology and the presence of cytoplasmic droplets were studied using the methodology described by Kawai et al. (2006). Using sperm head morphology, the percentage of spermatozoa with abnormal sperm heads, including triangular, collapsed and hammer heads or with a hairpin at the neck, was calculated. Using sperm tail morphology, sperm tails were classified into three categories: straight tail, proximal bent tail and distal bent tail including angled and hairpin forms. The percentage of every form was calculated. The percentage of spermatozoa with none, light-type or heavytype cytoplasmic droplets (CD) was also calculated.

\section{Testes histology}

The structure of both testes of three wild-type mice and three Wfs1KO mice were analyzed (totalling 12 testes). Samples were fixed in $10 \%$ buffered formalin and embed- ded in paraffin according to routine methods. Specimens were cut at $4 \mu \mathrm{m}$ thickness and stained with hematoxylin and eosin for examination by light microscopy. Specific cell counts were performed in each testicle in the seminiferous epithelium of five round-shaped seminiferous tubules, i.e. cells were counted in 10 tubules per mouse. Two independent, blind observers performed the cell counts.

\section{Measurement of hormonal levels}

Blood samples were taken from mice after they were killed by cervical dislocation. Samples were centrifuged for 15 minutes at $1000 \times \mathrm{g}$, 4 degrees. Serum was removed and samples analysed by ELISA kits (USCNLIFE, China) for testosterone and follicle-stimulating hormone (FSH). The optical density of the wells was determined with the ELISA reader SUNRISE (Tecan, Switzerland). 


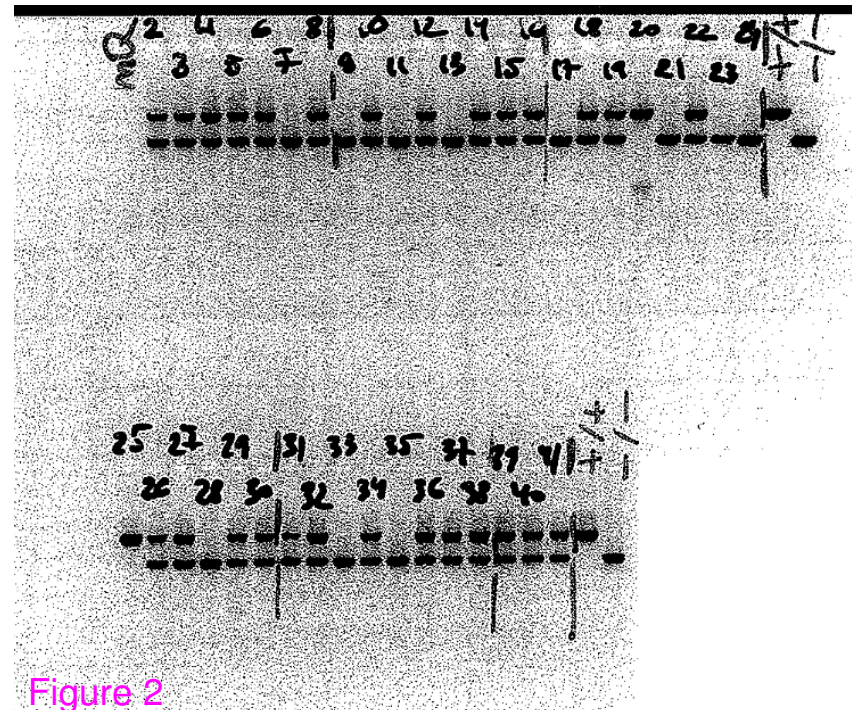

Figure 2

Gel electrophoresis of PCR product to genotype wfs I targeting products. Mice were genotyped by multiplex PCR for both alleles using primers Wfs IKO_wf2 5' TTGGCTTGTATTTGTCGGCC 3', NeoR I 5' GACCGCTATCAGGACATAGCG 3' and WfsKO_uniR2 5' CCCATCCTGCTCTCTGAACC 3'. The upper band is for the wild-type allele; the lower band is for the mutant allele. The presence of two bands indicates a heterozygous mutant mouse.

\section{Statistical analysis}

All data was analysed using the statistical software package, SAS version 9.1 (SAS Institute Inc, Cary, North Carolina, USA). The Chi-square test or Fisher's Exact Test (when expected values were $<5 \%$ ) was used to compare the fertility rates, and the Student's t-test was used to compare the sperm morphology, litter size, occurrence of the vaginal plugs and concentrations of the hormones between the groups. Mean \pm SEM are shown. P values < 0.05 were considered statistically significant.

\section{Results \\ The fertility study}

The pregnancy rate in female mice mated with $\mathrm{Wfs} 1 \mathrm{KO}$ males tended to be lower than in those mated with wt males: $15 / 78$ (19\%; 95\%CI 11.5 - 30.0) vs. $25 / 78$ (32\%; $95 \%$ CI $22.9-43.6), \mathrm{p}=0.1$. We noticed that in the Wfs1KO group there was one male who had pups with four out of the six females. This was more than 3 SD above the group's mean. When this male and his six females were excluded from the analysis, the pregnancy rate in females mated with Wfs $1 \mathrm{KO}$ males was significantly lower than the pregnancy rate in the control group: $11 / 72$ (15\%; 95\%CI 7.9 - 25.7) vs. 25/78 (32\%; 95\%CI 21.9 43.6). $\mathrm{P}<0.05$; (Figure 4).

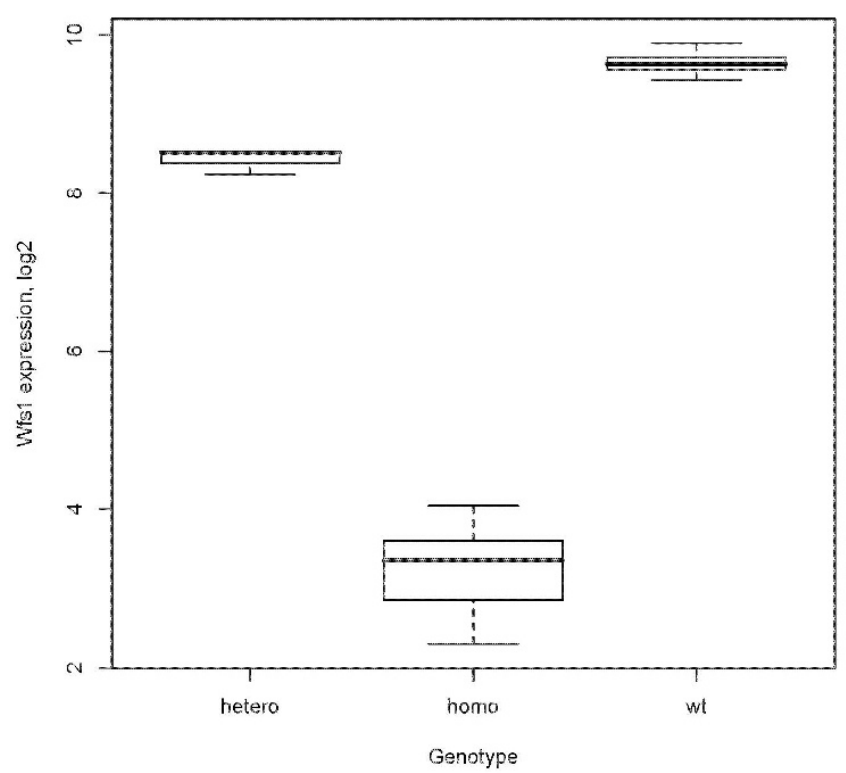

Figure 3

Wfs I mRNA expression is reduced in mutant mice. Genechip data (log2 transformed) from mice with three different genotypes illustrate the almost complete lack of Wfs I transcripts in homozygous mutant mice. In heterozygous mice the Wfs I mRNA level is half of that in wild-type mice.

In analysing the fertility of Wfs1 KO males, we found that five out of 13 of them did not have any litter, whereas all 13 of the control males had at least one litter ( $p<0.05)$. There was no significant difference in the litter size: $5.7 \pm$ 0.5 pups in the Wfs $1 \mathrm{KO}$ group vs. $6.6 \pm 0.5$ pups in the wt group. When analysing the occurrence of vaginal plugs we found that out of the six female mice who were mated with one male mouse, vaginal plugs occurred in $1.1 \pm 0.2$

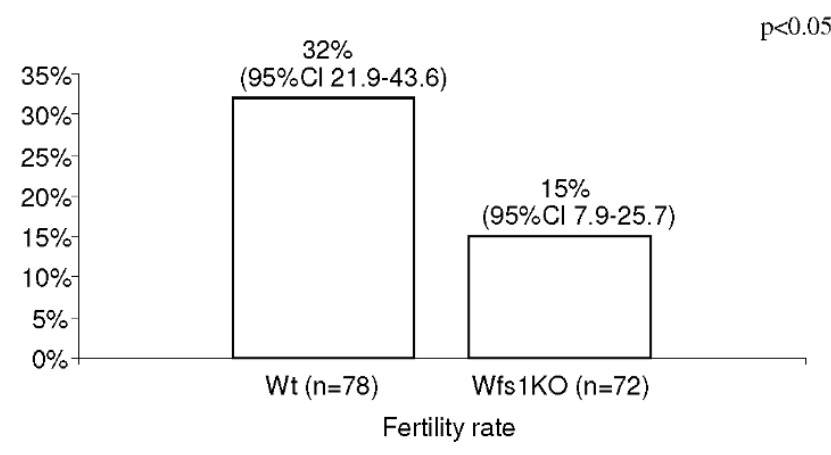

Figure 4

The fertility rate in percentages, with $95 \% \mathrm{Cl}$ in brackets, in 72 female wt mice mated with Wfs I KO $(n=12)$ male and in 78 female wt mice mated with wt male mice $(n=13)$. 
Table I: Sperm morphology in male mice according to Kawai et al (2006).

\begin{tabular}{llll}
\hline Characteristic & Wfs IKO (n= II) & wt $(\mathbf{n}=\mathbf{I 2 )}$ & p-value \\
\hline Motility & $78.0 \pm 2.8 \%$ & $70.0 \pm 3.4 \%$ & 0.04 \\
Straight motility & $66.0 \pm 3.5 \%$ & $58.0 \pm 4.4 \%$ & 0.08 \\
Sperm without CD & $57.2 \pm 4.9 \%$ & $68.7 \pm 5.4 \%$ & 0.07 \\
Light CD & $30.5 \pm 3.3 \%$ & $22.5 \pm 3.8 \%$ & 0.07 \\
Heavy CD & $12.3 \pm 1.8 \%$ & $8.8 \pm 1.8 \%$ & 0.09 \\
Straight tail & $53.1 \pm 1.5 \%$ & $50.3 \pm 1.7 \%$ & 0.1 \\
Proximal bent tail & $14.4 \pm 1.2 \%$ & $21.5 \pm 1.3 \%$ & 0.0003 \\
Distal bent tail & $32.5 \pm 2.3 \%$ & $28.2 \pm 1.7 \%$ & 0.07 \\
Hairpin at the neck & $9.7 \pm 0.7 \%$ & $9.7 \pm 0.8 \%$ & 0.5 \\
Abnormal head & $22.8 \pm 1.8 \%$ & $31.5 \pm 3.5 \%$ & 0.02 \\
\hline
\end{tabular}

Percentage of spermatozoa (out of 200) having the specific characteristic (mean $\pm \mathrm{SEM})$. (CD - cytoplasmic droplets).

a) light-type cytoplas mic droplets

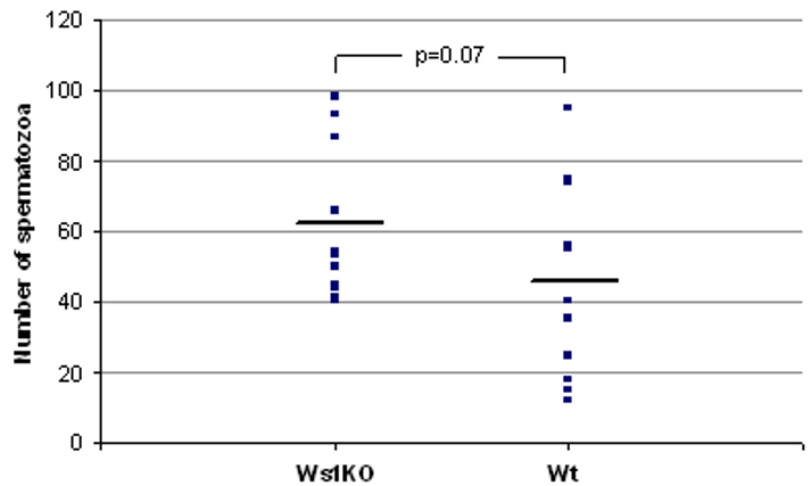

c) proximal bent tails

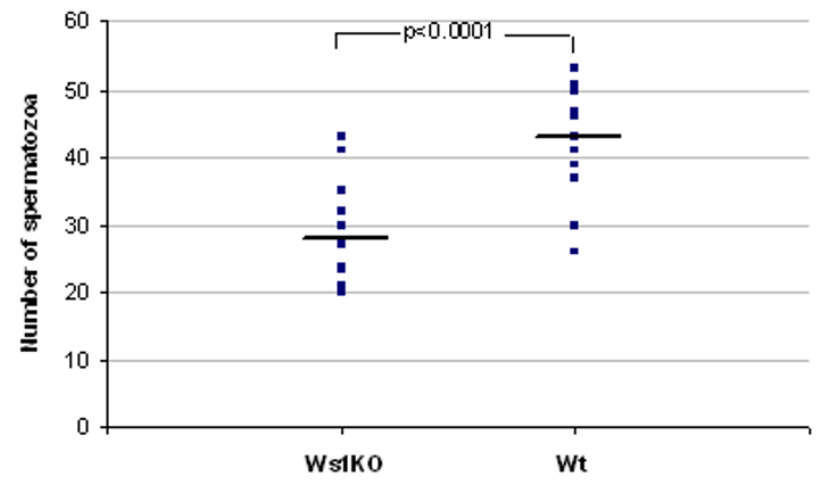

females in the Wfs1KO group, compared to their occurrence in $2.5 \pm 0.4$ females out of six in the wt group ( $\mathrm{p}<$ $0.05)$.

\section{Sperm motility and morphology study}

Sperm motility was not affected in Wfs1KO mice. Surprisingly, the mean percentage of motile sperm was even higher in the Wfs1KO mice than in the wt mice, whereas no statistical differences were observed in the percentage of straight motility (Table 1).

The sperm morphology study showed that Wfs1KO males had fewer proximal bent tails than wt males, but had fewer abnormal sperm heads than wt males (Table 1, Figure 5). The sperm of Wfs $1 \mathrm{KO}$ mice also tended to have more cytoplasmic droplets, both light-type and heavy-

\section{2) heavy-type cytoplasmic droplets}

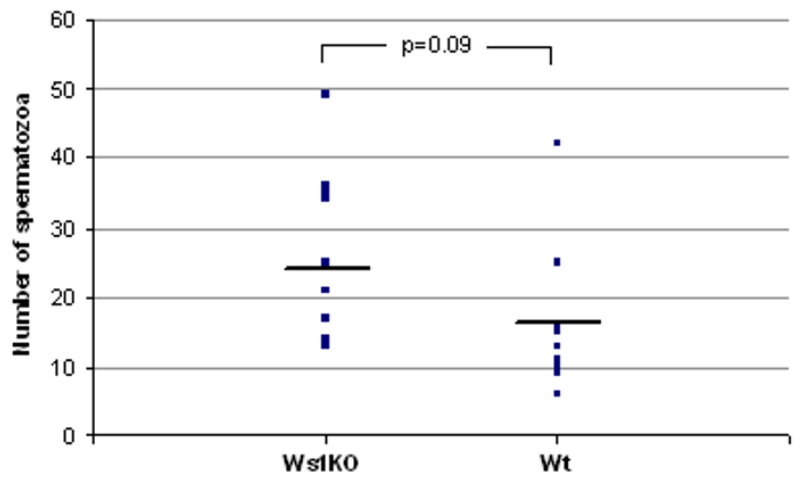

d) abnormal sperm heads

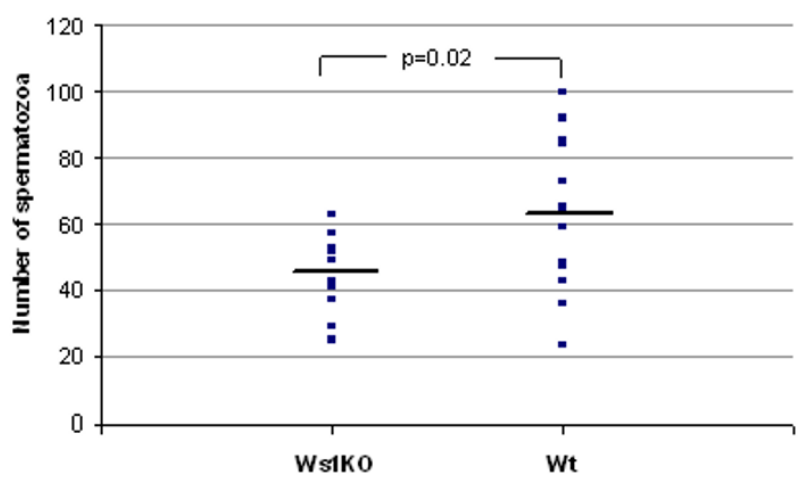

\section{Figure 5}

Four most important abnormalities in sperm morphology: a) light-type cytoplasmic droplets; b) heavy-type cytoplasmic droplets; c) proximal bent tails and d) abnormal sperm heads. The number of spermatozoa (out of 200) of each mouse having the specific characteristic is shown in dots. The mean number of the group is shown with a bold line. 
type, but the difference was not statistically significant (Table 1, Figure 5).

\section{Testes histology}

The organized architecture of the seminiferous epithelium of the seminiferous tubules seen in wt mice was lost in Wfs1KO mice (Figure 6). Contrary to the wild-type mice, the lumina of the seminiferous tubules in Wfs1-deficient mice have a typically irregular contour or the lumen may even be obliterated. Accumulation of eosinofilic luminal content is seen. Furthermore, several segments of these tubules have no spermatogenic cells at all (Figure 7). The seminiferous epithelium of Wfs1-deficient mice has reduced numbers of Spermatogonia and Sertoli cells, resulting in reduced sperm production (Table 2). There were no significant differences between the number and structure of Leydig cells between wt and Wfs1KO mice.

\section{Serum hormone concentration}

Serum testosterone and FSH concentrations in Wfs1KO males $(12.0 \pm 0.5 \mathrm{nmol} / \mathrm{l}$ and $5.6 \pm 0.1 \mathrm{mlU} / \mathrm{ml}$ respectively) did not different significantly from those in wt males $(11.5 \pm 0.7 \mathrm{nmol} / \mathrm{l}$ and $5.8 \pm 0.1 \mathrm{mlU} / \mathrm{ml}$ respectively).

\section{Discussion}

We have shown for the first time that male Wfs $1 \mathrm{KO}$ mice have reduced fertility compared to wt male mice. It is known that primary hypogonadism may occur in male patients with WS [2-5], but there has been no data about the fertility of patients with WS. One reason for this may be the few patients available with whom to carry out such a study, or the fact that other clinical symptoms, such as diabetes mellitus and vision or hearing impairments, dominate and precede the fertility problems. Conse-

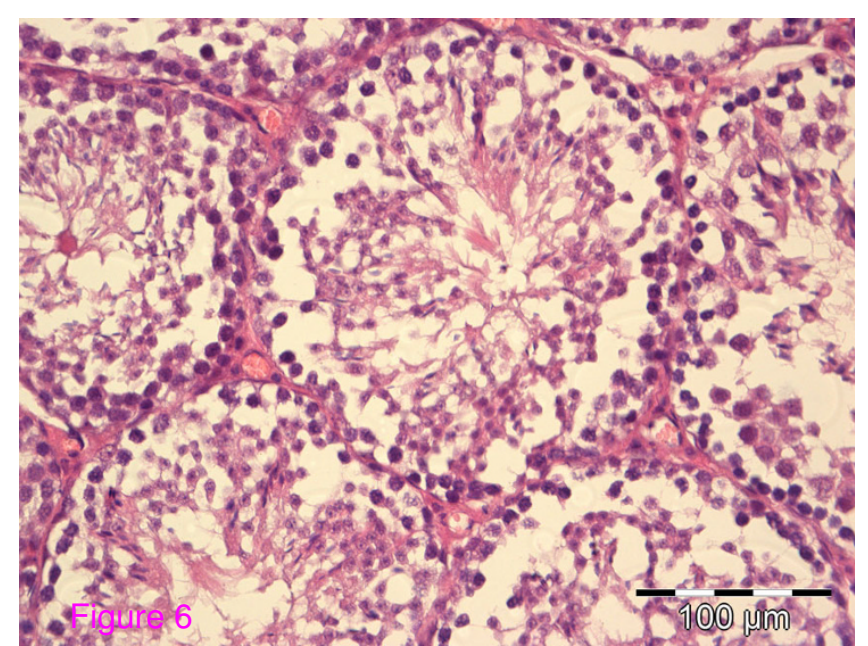

\section{Figure 6}

Normal seminiferous epithelium of the seminiferous tubules in a wild-type mouse. quently, we investigated whether Wfs $1 \mathrm{KO}$ male mice have reduced fertility and, if so, their possible causes.

The pregnancy rate of wt female mice was lower when mated with Wfs1KO male mice, than when mated with wt males. All wt males used in our study gave at least one litter with one female out of six, whereas only eight Wfs $1 \mathrm{KO}$ males out of 13 brought litters, indicating impaired fertility in male Wfs $1 \mathrm{KO}$ mice. In order to examine the possible mechanisms causing reduced fertility, we examined the sperm of the same males used in the fertility study. Having studied the motility and morphology of the sperm in the $\mathrm{Wfs} 1 \mathrm{KO}$ and wt groups, it was shown that the motility of spermatozoa in Wfs1KO mice was not impaired and was even slightly better than in the wt animals. However, many changes in sperm morphology were found. The most statistically significant difference was that the sperm of Wfs1KO mice contained fewer spermatozoa with proximal bent tails than the sperm of wt mice. The in vitro fertilization rate in mice has been shown to be positively correlated to proximal bent tails, but negatively to heavytype CD and distal bent tail. These last two characteristics were higher in Wfs $1 \mathrm{KO}$ mice compared to wt mice, but the difference did not reach statistical significance $(\mathrm{p}<$ 0.09 and 0.07 respectively). We did find that Wfs1KO males had fewer abnormal sperm heads. However, the impact of an abnormal sperm head on fertility has been found to be much smaller than the impact of different bent tails or cytoplasmic droplets as seen in the study by Kawai et al, in which a high percentage of abnormal sperm heads was related to a relatively good in vitro fertilization rate in mice [15].

Testicular histology showed a normal pattern of seminiferous epithelium in the tubules of wt mice, which was lost

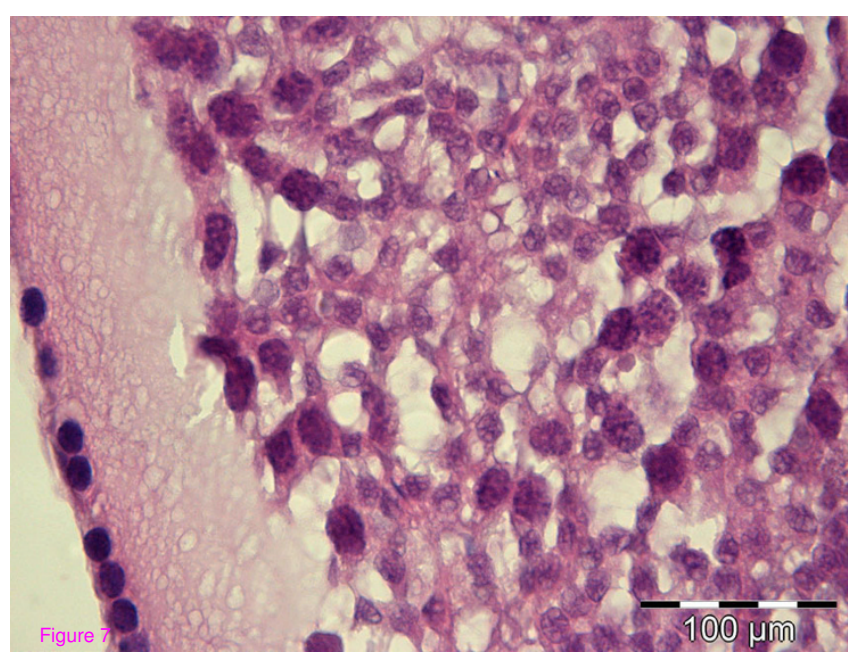

Figure 7

Altered structure of the seminiferous epithelium in a Wfs I KO mouse. 
Table 2: The number of cells (mean and \pm SEM) in the seminiferous epithelium of seminiferous tubules in wt and Wfs I KO mice.

\begin{tabular}{|c|c|c|c|c|c|c|}
\hline Group & SG & PSC & SSC & Spermatids & Sperms & Sertoli cells \\
\hline $\begin{array}{l}\text { Control } \\
(\mathrm{n}=3)\end{array}$ & $38.1 \pm 2.8$ & $54.3 \pm 0.8$ & $2.1 \pm 0.7$ & $134.1 \pm 6.1$ & $35.4 \pm 5.6$ & $9.2 \pm 1.0$ \\
\hline $\begin{array}{l}\text { WfsI } \\
(\mathrm{n}=3)\end{array}$ & $23.9 \pm 4.9 *$ & $47.2 \pm 7.0$ & $0.0 \pm 0.0$ & $110.0 \pm 15.2$ & $13.3 \pm 4.0^{*}$ & $6.4 \pm 0.5^{*}$ \\
\hline
\end{tabular}

SG - spermatogonia, PSC - primary spermatocytes, SSC - secondary spermatocytes.

$*_{p}<0.05$

in Wfs1KO mice. Several segments of seminiferous tubules in Wfs1 KO mice had no spermatogenic cells at all. The number of spermatogonia and Sertoli cells essential for effective spermatogenesis was decreased, leading to reduced sperm production. Thus, both sperm morphology and quantity is affected in Wfs $1 \mathrm{KO}$ mice. However, the number and structure of Leydig cells responsible for testosterone synthesis did not different between the Wfs $1 \mathrm{KO}$ and wt mice. This was also confirmed by normal testosterone levels in the two groups.

The mechanism by which wolframin deficiency may cause impaired fertility and changes in sperm morphology and quantity is not clear. One possible explanation may be through increased endoplasmic reticulum (ER) stress, which has been shown to cause progressive cell loss in pancreatic $\beta$-cells in Wfs 1 deficient mice $[10,16,17]$. ER stress enhances $W f s 1$ gene expression and $W f s 1$ deficient mice are more susceptible to ER stress-induced apoptosis than wild type mice [17]. Wfs1 is also expressed in the testes of mice [18], so it is possible that increased ER stress in the testes of Wfs $1 \mathrm{KO}$ mice may cause changes in spermatogenesis. Further studies, including electron microscopic studies of the endoplasmic reticulum of spermatozoa and the epithelium of seminiferous tubules in Wfs1KO mice, are necessary to confirm or reject our hypothesis.

Another possible reason for impaired fertility in Wfs1 KO mice may be due to changes in the hypothalamic-pituitary axis. It is known that patients with WS have disturbed anterior pituitary function [5], and our laboratory has shown changes in the gene expression levels of $\mathrm{GH}$, POMC and NPY in different parts of the brain [13]. Therefore, we also measured serum FSH and testosterone levels in these mice. We chose these two hormones because they both play an important role in spermatogenesis. However, we did not find any differences in their levels. Unfortunately we did not have enough serum to measure LH, but it is unlikely that serum LH concentrations would have been different due to comparable serum testosterone concentrations as well as the number and structure of Leydig cells. This observation suggests that it is unlikely that the impaired fertility in these mice would be caused by altered gonadotrophin levels. As the number of Sertoli cells was significantly lower in the Wfs $1 \mathrm{KO}$ group, inhibin $\mathrm{B}$ should be measured in further studies.

We cannot exclude the possibility that a part of the impaired fertility on Wfs $1 \mathrm{KO}$ male mice may be explained by different sexual behaviour. It is known that patients with WS frequently have psychiatric problems [19] and therefore may have defects in sexual behaviour. The occurrence of vaginal plugs in female mice was significantly lower when mated with Wfs $1 \mathrm{KO}$ males, in comparison to wt males. However, the occurrence of vaginal plugs is not a very reliable method, since the plug lasts only couple of hours and can easily be missed. Specially designed studies with video recording are necessary to clarify whether sexual behaviour in Ws1KO mice is different from wild-type mice.

\section{Conclusion}

In conclusion, Wfs $1 \mathrm{KO}$ male mice have impaired fertility, most likely due to changes in sperm morphology and reduced number of spermatogenic cells. The exact mechanism how the Wfs1 gene and its product, wolframin, influence sperm morphology needs to be clarified in further studies.

\section{Competing interests}

The authors declare that they have no competing interests.

\section{Authors' contributions}

KN conceived the study along with SK and VT, participated in its design and coordination and drafted the manuscript. AnK was responsible for the sperm morphology and motility study, and manuscript preparation. AA and MA were responsible for the histological study of the testes. AiK carried out the fertility study. EV supported the conducting of the studies. SK and VT conceived the study along with $\mathrm{KN}$, participated in its design and coordination and helped to draft the manuscript. All authors read and approved the final manuscript.

\section{Acknowledgements}

We gratefully acknowledge Mario Plaas for generating the Wfs IKO mice and Pille Kool for conducting statistical analysis. This study was supported by grants ETF7295 and ETF7479 from the Estonian Science Foundation, Grant No. 2695 from the Estonian Ministry of Education and Science, and 
by a grant from the European Union through the European Regional Development Fund and the Archimedes Foundation.

\section{References}

I. Smith CJ, Crock PA, King BR, Meldrum CJ, Scott RJ: Phenotypegenotype correlations in a series of wolfram syndrome families. Diabetes Care 2004, 27:2003-2009.

2. Barrett TG, Bundey SE: Wolfram (DIDMOAD) syndrome. J Med Genet 1997, 34(1 0):838-84I.

3. Barrett TG, Bundey SE, Macleod AF: Neurodegeneration and diabetes: UK nationwide study of Wolfram (DIDMOAD) syndrome. Lancet I995, 346(8988): |458-|463.

4. Peden NR, Gay JD, Jung RT, Kuwayti K: Wolfram (DIDMOAD) syndrome: a complex long-term problem in management. $Q$ J Med 1986, 58(226): I67-180.

5. Medlej R, Wasson J, Baz P, Azar S, Salti I, Loiselet J, Permutt A, Halaby $G$ : Diabetes mellitus and optic atrophy: a study of Wolfram syndrome in the Lebanese population. I Clin Endocrinol Metab 2004, 89(4): |656-|66|.

6. Collier DA, Barrett TG, Curtis D, Macleod A, Arranz MJ, Maassen JA, Bundey S: Linkage of Wolfram syndrome to chromosome 4p I6. I and evidence for heterogeneity. Am J Hum Genet 1996, 59(4):855-863.

7. Hofmann S, Philbrook C, Gerbitz KD, Bauer MF: Wolfram syndrome: structural and functional analyses of mutant and wild-type wolframin, the WFSI gene product. Hum Mol Genet 2003, I 2( I 6):2003-20I2.

8. Riggs AC, Bernal-Mizrachi E, Ohsugi M, Wasson J, Fatrai S, Welling C, Murray J, Schmidt RE, Herrera PL, Permutt MA: Mice conditionally lacking the Wolfram gene in pancreatic islet beta cells exhibit diabetes as a result of enhanced endoplasmic reticulum stress and apoptosis. Diabetologia 2005, 48(I I):23 I 3-232I.

9. Fonseca SG, Fukuma M, Lipson KL, Nguyen LX, Allen JR, Oka Y, Urano F: WFSI is a novel component of the unfolded protein response and maintains homeostasis of the endoplasmic reticulum in pancreatic beta-cells. J Biol Chem 2005, 280(47):39609-39615.

10. Yamada T, Ishihara H, Tamura A, Takahashi R, Yamaguchi S, Takei D, Tokita A, Satake C, Tashiro F, Katagiri H, Aburatani H, Miyazaki J, Oka Y: WFSI-deficiency increases endoplasmic reticulum stress, impairs cell cycle progression and triggers the apoptotic pathway specifically in pancreatic beta-cells. Hum Mol Genet 2006, I5( I 0): 1600-1609.

II. Sandhu MS, Weedon MN, Fawcett KA, Wasson J, Debenham SL, Daly A, Lango H, Frayling TM, Neumann RJ, Sherva R, Blech I, Pharoah PD, Palmer CN, Kimber C, Tavendale R, Morris AD, McCarthy MI, Walker M, Hitman G, Glaser B, Permutt MA, Hattersley AT, Wareham NJ, Barroso I: Common variants in WFS I confer risk of type 2 diabetes. Nat Genet 2007, 39(8):95 I-953.

12. Luuk H, Plaas M, Raud S, Innos J, Sutt S, Lasner H, Abramov U, Kurrikoff $\mathrm{K}$, Koks S, Vasar $\mathrm{E}$ : Wfs I-deficient mice display impaired behavioural adaptation in stressful environment. Behav Brain Res 2009, I 98(2):334-45.

13. Koks S, Soomets U, Paya-Cano JL, Fernandes C, Luuk H, Plaas M, Terasmaa A, Tillmann V, Noormets K, Vasar E, Schalkwyk LC: Wfs I gene deletion causes growth retardation in mice and interferes with the growth hormone pathway. Physiol Genomics 2009, 37(3):249-259.

14. Schalkwyk LC, Fernandes C, Nash MW, Kurrikoff K, Vasar E, Koks S: Interpretation of knockout experiments: the congenic footprint. Genes Brain Behav 2007, 6(3):299-303.

15. Kawai Y, Hata T, Suzuki O, Matsuda J: The relationship between sperm morphology and in vitro fertilization ability in mice. J Reprod Dev 2006, 52(4):56I-568.

16. Ueda K, Kawano J, Takeda K, Yujiri T, Tanabe K, Anno T, Akiyama M, Nozaki J, Yoshinaga T, Koizumi A, Shinoda K, Oka Y, Tanizawa Y: Endoplasmic reticulum stress induces $\mathrm{Wfs} I$ gene expression in pancreatic beta-cells via transcriptional activation. Eur J Endocrinol 2005, I 53(I): I67-I76.

17. Ishihara H, Takeda S, Tamura A, Takahashi R, Yamaguchi S, Takei D, Yamada T, Inoue H, Soga H, Katagiri H, Tanizawa Y, Oka Y: Disruption of the WFSI gene in mice causes progressive beta-cell loss and impaired stimulus-secretion coupling in insulin secretion. Hum Mol Genet 2004, I 3( I I): I I 59- I I70.
18. Koks S, Luuk H, Plaas M, Vasar E: Expressional profile of the WFSI gene. In WFSI Protein (Wolframin): Emerging Link Between the Emotional Brain and Endocrine Pancreas Edited by: Koks S, Vasar E. Kerala: Research Signpost; 2008:7I-86.

19. Swift RG, Sadler DB, Swift M: Psychiatric findings in Wolfram syndrome homozygotes. Lancet 1990, 336(87 I 6):667-669.
Publish with Bio Med Central and every scientist can read your work free of charge

"BioMed Central will be the most significant development for disseminating the results of biomedical research in our lifetime. "

Sir Paul Nurse, Cancer Research UK

Your research papers will be:

- available free of charge to the entire biomedical community

- peer reviewed and published immediately upon acceptance

- cited in PubMed and archived on PubMed Central

- yours - you keep the copyright
BioMedcentral 